\title{
Local application of low-dose insulin in improving wound healing after deep burn surgery
}

\author{
CHEJIANG WANG $^{1 *}$, JIAZHE WANG $^{2 *}$ and JIANKE FENG ${ }^{1}$ \\ ${ }^{1}$ Department of Burn and Plastic Surgery, The First Affiliated Hospital of Hebei Medical University, \\ Shijiazhuang, Hebei 050031; ${ }^{2}$ Department of Burn and Plastic Surgery, General Hospital \\ of Chinese People's Armed Police Forces, Beijing 100039, P.R. China
}

Received February 8, 2016; Accepted August 23, 2016

DOI: $10.3892 /$ etm.2016.3645

\begin{abstract}
The clinical effects of local application of low-dose insulin in improving wound healing after deep burn self-skin transplantation surgery were examined. Fifty-eight patients with deep burns were selected and randomly divided into 3 groups. In the blank control group, normal saline was injected to the subcutaneous tissue of wounds; in large dose insulin group, $1.0 \mu$ long-term suspended zinc insulin was locally injected; and in the low-dose insulin group, $0.1 \mu$ long-term suspended zinc insulin was locally injected. The healing effects were compared. After 7 and 14 days of treatments, wound surface area in the low-dose group was significantly smaller than in the other groups, and differences were statistically significant $(\mathrm{P}<0.05)$; wound healing duration and infection rate for patients in the low-dose group were significantly lower, class A healing rate was significantly improved, and the differences were statistically significant $(\mathrm{P}<0.05)$. Insulin resistance index (HOMA-IR) in the low-dose group was significantly lower, insulin secretion index (HOMA- $\beta$ ) and the insulin sensitivity index (HOMA-ISI) significantly increased. The expression levels of vascular endothelial growth factor and tumor necrosis factor- $\alpha$ in local tissue for the low-dose group were significantly higher than those in the other two groups. Differences were statistically significant $(\mathrm{P}<0.05)$. In conclusion, local application of low-dose insulin can effectively improve wound healing after deep burn surgeries.
\end{abstract}

\section{Introduction}

Deep burn usually cause stress hyperglycemia, which can influence the healing process, delay the healing process and

Correspondence to: Dr Jianke Feng, Department of Burn and Plastic Surgery, The First Affiliated Hospital of Hebei Medical University, 89 Donggang Road, Shijiazhuang, Hebei 050031, P.R. China

E-mail: feng_jianke1@163.com

*Contributed equally

Key words: insulin, deep burning, wound healing, HOMA-IR, HOMA- $\beta$, HOMA-ISI, vascular endothelial growth factor negatively affect the quality of the wounds (1). Prior studies showed that severe burning secondary insulin resistance is an independent risk factor (2). Advanced glycosylation of end products play a biological role through the combination with transmembrane receptor (3).

It has been shown that local application of insulin could stimulate the protein biosynthesis, correct negative nitrogen balance, and improves tissue regeneration in the wound region (4). Possible reasons for these events include epidermal thickness, increase in the number of nails of feet, the fibroblast activation, being in $\mathrm{S}$ phase of cell cycle, increase in the number of cells in G2/M phase, and the increase in the level of growth factors such as epidermal growth factor and vascular endothelial growth factor (VEGF) (5). Although local application of insulin can improve the healing rate and shorten healing duration (6), there is no consensus on the application dose of insulin. Application of large doses of insulin may negatively affect the immune system and increase the infection rate (7). Therefore, the suitable dose of insulin to be locally applied after deep burn surgeries is worth evaluating.

\section{Patients and methods}

Patients and study criteria. Between February 2013 and February 2014, 58 patients, all diagnosed with deep burns in the General Hospital of Chinese People's Armed Police Forces (Shanghai, China), were enrolled in this study. The following inclusion criteria were used: i) all patients were $\geq 18$ years but $<75$ years; ii) patients were conscious and were treated for the first time; and iii) informed consent was obtained. The following exclusion criteria were used: i) patients with serious infection, shock, unmanageable intense pain, inhalation pulmonary injury, coagulation disorders, severe organ dysfunctions such as heart, liver and kidney; ii) patients with skin transplantation failure, and serious diseases; and iii) pregnant patients and patients with an estimated lifespan of $<12$ months were excluded from this study.

This study was approved by the Ethics Committee of the General Hospital of Chinese People's Armed Police Forces. Using the random number method, patients were divided into three groups: i) blank control group (16 patients), ii) large-dose insulin group (19 patients), and iii) low-dose insulin group (23 patients). In the control group, there were 11 males and 
5 females; with ages ranging from 37 to 63 years with the average age of $49.8 \pm 12.5$ years; the duration from burning to hospitalization ranged from $30 \mathrm{~min}$ to $3 \mathrm{~h}$ with the average duration of $1.2 \pm 0.3 \mathrm{~h}$. Twelve patients had deep second degree burns while 4 patients suffered from third degree burns; burned surface area ranged from 25 to $83 \%$ of total body surface area (TBSA) with the average of $66.9 \pm 15.7 \%$. In the large dose group, there were 13 males and 6 females aged from 35 to 65 years with the average of $48.7 \pm 13.6$ years; the duration from burning to hospitalization ranged from $45 \mathrm{~min}$ to $2.6 \mathrm{~h}$ with the average duration of $1.4 \pm 0.5 \mathrm{~h}$; 14 patients had deep second degree burns and 5 had deep third degree burns; burning surface area made up 26 to $85 \%$ of TBSA with the average of $65.7 \pm 14.3 \%$. In the low-dose group, there were 17 males and 6 females; aged from 36 to 68 years with the average age of $50.3 \pm 14.6$ years. The duration from burning to hospitalization ranges from $35 \mathrm{~min}$ to $3.5 \mathrm{~h}$ with the average duration of $1.7 \pm 0.6 \mathrm{~h}$; 16 patients had deep second degree burns while 7 patients had deep third degree burns. Burning surface area was 28 to $89 \%$ of TBSA with the average of $69.8 \pm 14.7 \%$. The gender, age, duration of hospitalization, burned degree and TBSA were compared, and the differences demonstrated no statistical significance $(\mathrm{P}>0.05)$.

Therapeutic method. According to therapeutic principles of burning, all patients were given treatments such as fluid infusion, infection control, nutrition enhancement, wound debridement and self-skin transplantation, while at the same time, normal saline was injected to the subcutaneous tissue in burned areas in the control group; $1.0 \mu$ long-term suspended zinc insulin was locally injected in the large dose group; and $0.1 \mu$ long-term suspended zinc insulin was locally injected in the low-dose group. Long-term suspended zinc insulin (batch no. 2314054; Beijing Biochemistry Pharmaceutical Co., Beijing, China) was diluted in $2 \mathrm{ml}$ isotonic saline, and was injected under the wound. Debridement, disinfection and the observation of wound healing conditions were carried out regularly.

Observation indexes. Wound surface area, wound healing duration, infection rate and class A healing rate of patients in all 3 groups were compared after 7 and 14 days of treatment. HOMA-IR, HOMA- $\beta$ and HOMA-ISI as well as the expression levels of VEGF and local tissue tumor necrosis factor- $\alpha$ (TNF- $\alpha$ ) (in tissues at the junction of healing and unhealing wounds) were compared after 7 and 14 days treatment using ELISA (Beijing North Institute of Biological Technology, Beijing, China).

Two samples of peripheral venous blood were collected at limosis condition, one $2 \mathrm{ml}$ sample and the second $6 \mathrm{ml}$. The $2 \mathrm{ml}$ blood sample was used for fasting blood glucose (FBG) examination. AU5400 biochemical detector was used and glucose oxidase method was adopted. The $6 \mathrm{ml}$ blood sample was kept for $1 \mathrm{~h}$, after 20 min centrifugation at 2,000 x g, upper portion of the serum was separated and placed at $-60^{\circ} \mathrm{C}$ for the examination of fasting insulin (FINS), C-peptide and glucagon (GL). Radioimmunoassay reagents were provided by Beijing North Institute of Biological Reagents, radioimmunoassay measuring instrument GC1200 was provided by Anhui USTC ZonKia Scientific Instruments Co., Ltd. (Anhui, China), and the radioimmunoassay measuring process was conducted by two nuclear medicine professionals. HOMA method was employed for the calculation: HOMA-IR $=$ FBG $(\mathrm{mmol} / \mathrm{l}) \times$ FINS $(\mu \mathrm{U} /$ $\mathrm{ml}) / 22.5$, HOMA- $\beta=20 \times \mathrm{FINS}(\mu \mathrm{U} / \mathrm{ml}) /[\mathrm{FBG}(\mathrm{mmol} / \mathrm{l})-3.5]$, $\mathrm{ISI}=\log [100 / \mathrm{FBG}(\mathrm{mmol} / \mathrm{l}) \times$ FINS $(\mu \mathrm{U} / \mathrm{ml})]$.

Statistical method. SPSS 20.0 statistical software (Chicago, IL, USA) was used for data processing. Measurement data are expressed as mean \pm standard deviation (SD), variance analysis was used for comparison among groups. Enumeration data were expressed as a percentage $(\%)$, and the $\chi^{2}$ test was used for comparison among groups. $\mathrm{P}<0.05$ was considered statistically significant.

\section{Results}

Comparison of wound-healing conditions. The patients' wound surface area in the three groups was reduced after 7 and 14 days. Wounds in the low-dose group decreased most significantly, and the differences were statistically significant $(\mathrm{P}<0.05)$ (Table I).

Comparison of insulin resistance indexes. HOMA-IR in the low-dose group was significantly lower after 7 and 14 days of treatment, while HOMA- $\beta$ and HOMA-ISI in the low-dose group significantly increased after 7 and 14 days, and differences were statistically significant $(\mathrm{P}<0.05)$ (Table II).

Comparison of VEGF and TNF- $\alpha$ levels. The expression levels of VEGF and TNF- $\alpha$ in local tissues in low-dose group were significantly higher than those in the other two groups after 7 and 14 days of treatment, and differences were statistically significant $(\mathrm{P}<0.05)$ (Table III).

\section{Discussion}

Wound healing is a process through which epithelio-reproductive tissue continuously form new skin tissue outwards. This process involves a highly coordinated and mutual regulating process of joint participation of multiple factors such as inflammatory cells, repairing cells, extracellular matrix and cytokines (8). Through the study on the impact of local application of nerve growth factors-insulin composite gel to deep second degree empyrosis wound healing of rats with diabetes, it was verified that as an important endogenic and ectogenic hormone, insulin played an important role in many biological adjustment processes, such as protein synthesis, glucose transport, haemodynamics, fatty acid metabolism and the reduction of the occurrence of metabolic disorders after burning incidences (9). The molecular mechanism of insulin improving wound healing may involve implication of growth factors secreted by multiple cells, such as VEGF, TNF- $\alpha$ and IL-1 (10), which all played important roles in the process of wound healing. VEGF is the most powerful mitogen of vascular endothelial cells in the family of growth factors. VEGF can specifically promote the division and proliferation of vascular endothelial cells, and increase the permeability of capillaries, which further induce the formation of new blood vessels (11). Prior studies showed that the VEGF expression in normal tissues was relatively weak, but its expression in wound 
Table I. Comparison of wound-healing conditions.

\begin{tabular}{|c|c|c|c|c|c|}
\hline \multirow[b]{2}{*}{ Groups } & \multicolumn{2}{|c|}{ Wound surface area (\% TBSA) } & \multirow{2}{*}{$\begin{array}{l}\text { Healing duration } \\
\text { (days) }\end{array}$} & \multirow{2}{*}{$\begin{array}{l}\text { Wound infection } \\
\text { [cases }(\%)]\end{array}$} & \multirow{2}{*}{$\begin{array}{c}\text { Class A healing } \\
\text { [cases }(\%)]\end{array}$} \\
\hline & 7 days & 14 days & & & \\
\hline Control $(n=16)$ & $52.3 \pm 9.7$ & $42.1 \pm 7.8$ & $24.1 \pm 7.5$ & $5(31.3)$ & $7(43.8)$ \\
\hline Large dose $(n=19)$ & $53.7 \pm 9.3$ & $43.4 \pm 8.1$ & $25.3 \pm 7.7$ & $3(15.8)$ & $11(57.9)$ \\
\hline Low dose $(n=23)$ & $42.7 \pm 8.5$ & $33.2 \pm 8.1$ & $16.4 \pm 6.3$ & $1(4.3)$ & $19(82.6)$ \\
\hline $\mathrm{F}\left(\chi^{2}\right)$ & 3.335 & 3.712 & 3.927 & 7.171 & 8.715 \\
\hline P-value & 0.037 & 0.029 & 0.025 & $<0.001$ & $<0.001$ \\
\hline
\end{tabular}

TBSA, total body surface area.

Table II. Comparison of insulin resistance indexes.

\begin{tabular}{|c|c|c|c|c|c|c|}
\hline Groups & 7 days HOMA-IR & 14 days HOMA-IR & 7 days HOMA- $\beta$ & 14 days HOMA- $\beta$ & 7 days ISI & 14 days ISI \\
\hline Control & $5.39 \pm 0.47$ & $4.84 \pm 0.52$ & $104.35 \pm 43.56$ & $115.63 \pm 46.35$ & $1.62 \pm 0.17$ & $1.74 \pm 0.22$ \\
\hline Large dose & $5.84 \pm 0.42$ & $4.85 \pm 0.56$ & $173.51 \pm 50.39$ & $191.26 \pm 48.52$ & $1.75 \pm 0.19$ & $1.92 \pm 0.32$ \\
\hline Low dose & $2.34 \pm 0.06$ & $2.08 \pm 0.07$ & $295.75 \pm 73.62$ & $345.62 \pm 82.41$ & $2.62 \pm 0.35$ & $2.92 \pm 0.46$ \\
\hline $\mathrm{F}$ & 4.127 & 4.236 & 4.625 & 4.458 & 4.957 & 4.867 \\
\hline P-value & 0.023 & 0.021 & 0.017 & 0.014 & 0.013 & 0.015 \\
\hline
\end{tabular}

ISI, insulin sensitivity index.

Table III. Comparison of VEGF and TNF- $\alpha$ levels.

\begin{tabular}{lccrr}
\hline Groups & 7 days VEGF $(\mathrm{pg} / \mathrm{ml})$ & 14 days VEGF & 7 days TNF- $\alpha(\mathrm{ng} / \mathrm{l})$ & 14 days TNF- $\alpha$ \\
\hline Control & $76.85 \pm 24.53$ & $75.62 \pm 25.74$ & $46.92 \pm 25.74$ & $43.92 \pm 21.32$ \\
Large dose & $154.67 \pm 59.82$ & $163.82 \pm 44.57$ & $65.43 \pm 24.57$ & $69.87 \pm 23.35$ \\
Low dose & $264.52 \pm 62.34$ & $298.61 \pm 58.56$ & $124.57 \pm 43.62$ & $165.94 \pm 38.37$ \\
F & 5.327 & 5.129 & 5.947 & 5.658 \\
P-value & $<0.001$ & $<0.001$ & $<0.001$ & $<0.001$ \\
\hline
\end{tabular}

VEGF, vascular endothelial growth factor; TNF- $\alpha$, tumor necrosis factor- $\alpha$.

healing was enhanced (12). During the process of chronic wound healing, the enhanced amplitude of VEGF expression is significantly smaller than that of normal wound. TNF- $\alpha$ is a kind of small molecular protein secreted by macrophages, which has a wide range of biological activities. It can adjust cellular functions, immunity and inflammatory reaction processes and has antitumor property (13). TNF- $\alpha$ at normal levels can resist bacterial and viral infections and improve tissue repairs. It has been suggested that TNF- $\alpha$ can express type 1 histocompatibility antigen through the process of mitosis acted on fibroblasts, promote the growth of granulation tissue, and therefore promote wound healing. TNF- $\alpha$ can also activate $\mathrm{T}$ lymphocyte, stimulate the differentiation of fibroblasts and the production of collagenous fibers to promote wound healing (14).

In the present study, we concluded that after 7 or 14 days of treatment, wound surface area in the low-dose group was significantly smaller compared to those in other groups. Wound healing duration and infection rate in the low-dose group were significantly lower and class A healing rate was significantly improved. This means the effects of lowdose insulin in improving wound healing may be better than that of large doses. HOMA-IR in the low-dose group was significantly lower, while HOMA- $\beta$ and HOMA-ISI in the low-dose group were significantly higher. All differences were statistically significant. This showed that low-dose insulin was more effective than the large dose in improving insulin resistance, promoting insulin secretion and increasing insulin sensitivity. The expression levels of VEGF and TNF- $\alpha$ of local tissues in the low-dose group were significantly higher than those in other two groups. This confirms that low dose of insulin was more effective than large dose in increasing cell factors involved in the wound-healing process. 
A possible shortcoming for the present study was the relatively small sample group and relatively short observation time. Additionally, the division of insulin dose could be more detailed, no relevant analyses were carried out between wound healing and insulin dose, insulin indexes and cellular factors. It is desirable that more rigorous basic animal model experiments and larger scale clinical randomized controlled trials and studies to be carried out, which can provide new ideas for deep burn treatments.

\section{References}

1. Finnerty CC, Ali A, McLean J, Benjamin N, Clayton RP, Andersen CR, Mlcak RP, Suman OE, Meyer W and Herndon DN: Impact of stress-induced diabetes on outcomes in severely burned children. J Am Coll Surg 218: 783-795, 2014.

2. Li J, Zhu L, Xu M, Han J, Bai X, Yang X, Zhu H, Xu J, Zhang X, Gong Y, et al: Selective decontamination of the digestive tract ameliorates severe burn-induced insulin resistance in rats. Burns 41: 1076-1085, 2015.

3. Paradela-Dobarro B, Rodiño-Janeiro BK, Alonso J, Raposeiras-Roubín S, González-Peteiro M, González-Juanatey JR and Álvarez E: Key structural and functional differences between early and advanced glycation products. J Mol Endocrinol 56: 23-37, 2016.

4. Chen X, Liu Y and Zhang X: Topical insulin application improves healing by regulating the wound inflammatory response. Wound Repair Regen 20: 425-434, 2012.

5. Lima MH, Caricilli AM, de Abreu LL, Araújo EP, Pelegrinelli FF, Thirone AC, Tsukumo DM, Pessoa AF, dos Santos MF, de Moraes MA, et al: Topical insulin accelerates wound healing in diabetes by enhancing the AKT and ERK pathways: a double-blind placebo-controlled clinical trial. PLoS One 7: e36974, 2012.

6. Bulik CC, Wiskirchen DE, Shepard A, Sutherland CA, Kuti JL and Nicolau DP: Tissue penetration and pharmacokinetics of tigecycline in diabetic patients with chronic wound infections described by using in vivo microdialysis. Antimicrob Agents Chemother 54: 5209-5213, 2010.
7. Galeano M, Polito F, Bitto A, Irrera N, Campo GM, Avenoso A, Calò M, Lo Cascio P, Minutoli L, Barone M, et al: Systemic administration of high-molecular weight hyaluronan stimulates wound healing in genetically diabetic mice. Biochim Biophys Acta 1812: 752-759, 2011

8. Lin TS, Abd Latiff A, Abd Hamid NA, Wan Ngah WZ, Mazlan M: Evaluation of topical tocopherol cream on cutaneous wound healing in streptozotocin-induced diabetic rats. Evid Based Complement Alternat Med 2012: 491027, 2012. doi: $10.1155 / 2012 / 491027$

9. Apikoglu-Rabus S, Izzettin FV, Turan P and Ercan F: Effect of topical insulin on cutaneous wound healing in rats with or without acute diabetes. Clin Exp Dermatol 35: 180-185, 2010

10. Zhang YF, Li HZ, Wang XY, Ma HC, Wu Y, Yuan XH and Chu YH: Morphology of hypertrophic scar tissues and expressions of vascular endothelial growth factor and transforming growth factor beta activated kinase 1 in these tissues. Zhongguo Yi Xue Ke Xue Yuan Xue Bao 37: 446-450, 2015 (In Chinese).

11. Fleetwood F, Güler R, Gordon E, Ståhl S, Claesson-Welsh L and Löfblom J: Novel affinity binders for neutralization of vascular endothelial growth factor (VEGF) signaling. Cell Mol Life Sci 9: $1-3,2015$

12. Liu LY, Hou YS, Chai JK, Hu Q, Duan HJ, Yu YH, Yin HN, Hao DF, Feng G,Li T, et al: Basic fibroblast growth factor/vascular endothelial growth factor in the serum from severe burn patients stimulates the proliferation of cultured human umbilical cord mesenchymal stem cells via activation of Notch signaling pathways. J Trauma Acute Care Surg 75: 789-797, 2013.

13. Stromps JP, Fuchs P, Demir E, Grieb G, Reuber K and Pallua N: Intraalveolar TNF- $\alpha$ in combined burn and inhalation injury compared with intraalveolar interleukin-6. J Burn Care Res 36: e55-e61, 2015.

14. O'Halloran E, Kular J, Xu J, Wood F and Fear M: Non-severe burn injury leads to depletion of bone volume that can be ameliorated by inhibiting TNF- $\alpha$. Burns 41: 558-564, 2015. 